\title{
Integrated Quantitative Business Network Planning: Towards a New Understanding of Supply Chain Management
}

\author{
Michael Jahr*
}

\author{
European University of Applied Sciences (EUFH), Department of Industrial Management, Chair for Business \\ Administration and Quantitative Methods, Hammer Landstr. 89, 41460 Neuss, Germany
}

\begin{abstract}
In business management quantitative modelling is a core competency. It enables structuring various complex problems; reduce systems to their relevant elements and to make objective and clear decisions. This especially applies to production-distribution networks which are formed by multiple independent and globally active companies. Here, individual goals and collective tasks meet so that experienced-based knowledge is no longer satisfactory. A literature review showed that there is no satisfactory concept available for superior network and quantitative operational management in multi-tier business networks. Therefore, in this article we focus quantitative supply chain models as starting point for stipulations among independent network partners. First, we deduce the main elements of quantitative modelling for inter- and intra-organisational production-distribution planning. Thereby, we present an extension of the Two-Stage-Production-Distribution-Problem which can be used as starting point for iterative supply chain coordination. Based on a literature review we introduce a novel pivotal point supply chain management model. The approach induces ongoing alignment of the strategic, tactic and operative tasks. On each level of this hierarchical planning frame specific plans are computed for comparison and adjustment. The advantages of this approach can be found in the reliable objective basis for negotiations and the repeatable combined inter- and intra-organisational management.
\end{abstract}

Keywords: Mathematical Programming, Production Distribution Networks, Quantitative Management, Supply Chain Reference Model, Pivotal Point Coordination.

\section{QUANTITATIVE MANAGEMENT OF INTEGRATED SUPPLY CHAIN NETWORKS OVER THE EXPERIENCED-BASED MANAGEMENT OF AN INDIVIDUAL BUSINESS}

In the past business management was seen as a compound of different specialized strategic and operational disciplines, e.g. marketing, controlling, operations management etc. Existing differences in the way management was defined, i.e. the strategic market based view or the operational resource based view, led to academic and job specializations. The role of combining the different fields to an aligned business strategy is up to the entrepreneur or the highest corporate management level. In this way businesses and companies were, and in many cases still are, managed and organized as individual entities on procurement and sales markets. Though, at the end of the last century experts in theory and practice became aware that companies no longer act as individuals but are integrated in vertical and horizontal business networks [1-3]. As a consequence, nowadays entire networks or supply chains compete on global markets rather than separated companies [3]. An isolated optimization of business processes in the fields of procurement, production and sales proofed to be insufficient, even leading to severe undesirable

*Address correspondence to this author at the European University of Applied Sciences (EUFH), Department of Industrial Management, Chair for Business Administration and Quantitative Methods, Hammer Landstr. 89, 41460 Neuss, Germany; Tel: ++49-2131/40306-930; E-mail: m.jahr@eufh.de developments as for example the well-known bullwhipeffect [4]. A new discipline was coined, the supply chain management (SCM), which became nearly the most investigated research field in management, including a wide range of publications [2]. Yet, in many cases only traditional viewpoints and methodologies were put on an identical level with the new expression disregarding the advanced character of SCM. Nevertheless, various authors emphasized that supply chain management is more than just a renaming [1]. Instead it is potentially the most important management advancement in the last decades. To substantiate this hypothesis we start at what supply chain management is about. From the many existing good definitions of SCM [3] we outline the following version: Supply Chain Management is the coordination of businesses in integrated networks focussing the synchronization of material, information and financial flows with the objective of meeting customer needs, creating operational efficiency and a strong competitive position of the network. Apparently supply chain management merges operational and strategic processes in an unprecedented way. A strong differentiation in management disciplines is no longer possible or reasonable. It is therefore logical to consider SCM as independent widespread concept and not as a component of a superordinate management [5]. Furthermore, it is also clear that the abundance of business processes cannot be managed without quantitative decision support. Decision makers are not 
able to oversee any number of inter and intraorganisational multilevel processes with strong interrelationships only by experienced-based knowledge. Here, we focus on production-distribution networks. As a consequence, the aforementioned operational processes, i.e. procurement, production and distribution, are mainly considered. Numerous contributions in the field of supply chain modelling offer a wide range of supporting quantitative solution approaches. A review showed that these are predominantly sector-specific and not explicitly embedded in a holistic management concept. Then again, there are reference models for the broad supply chain management field in which the SCOR model is one the most well-known representatives [5]. These, for their part, regard quantitative methodology as important element, but not as a possible starting or pivotal point [6]. For two reasons this is inappropriate. The first reason is the aforementioned limited cognitive capacity of decision makers. Business networks encompassing multiple tiers, companies, products and periods cannot be managed only based on qualitative criteria. The second reason is that meanwhile progresses in information systems enable computing and application of extensive models in acceptable computing time. Therefore, it is no longer transparent to refer to a limited practicability of quantitative models. Within business networks with multiple independent partners the processes and activities must be coordinated. This requires swift procedures to stipulate for example production quantities. Thus, the individual supply chain managers need a common starting point for the interand intra-organisational management. By now, there is no explicit approach available which considers quantitative planning as starting point in independent business networks. So, in this article we intend to close the gap between quantitative supply chain modelling and holistic supply chain management and introduce a reference model with quantitative supply chain models as pivotal point. The article is structured as follows. In section two we discuss the basics of supply chain modelling and present a simple extension of the TwoStage-Production-Distribution-Problem as pattern for quantitative models suitable as centre. Then, in section three a novel reference model is presented based on a literature review which utilises quantitative supply chain modelling as pivotal point for the management activities. Finally, in section four, we show implications for management practice and business management teaching and give some concluding remarks.

\section{SUPPLY CHAIN MODELLING}

\subsection{Basics of Mathematical Supply Chain Modelling}

Any mathematical model must be suitable for swift operational plan computing which, in turn, is necessary for decision support. Management is then understood as repeated plan computing and comparison. In business networks formed by numerous companies the efficient information exchange, i.e. transparent communication, is the decisive point for the competitive strength. Especially the coordination of productiondistribution processes is central. In this context, quantitative plans provide objective decision criteria and make effective coordination possible at all. Therefore, we favour discrete modelling with big-timebuckets used in hierarchical planning (see Figure 1). In practice frequently a stepwise planning, known as MRP, can be observed including a successive independent planning of procurement, production and distribution. Thus, in this traditional planning the relationships among the functional areas are disregarded leading to infeasible plans. Hierarchical planning pursues timely downgrading with simultaneous planning of all activities in one model.

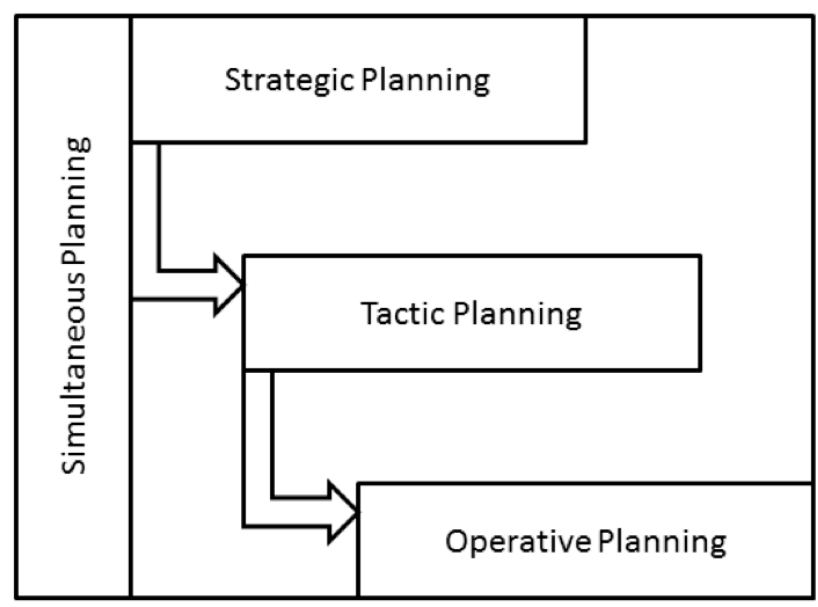

Figure 1: Hierarchical Planning.

Hence, long-term strategic planning sets the standards for mid-term tactical planning. At the end tactical targets are the basis for short-term operational plans. In this respect, the same or at least similar structured models can be used on all three levels only differing in their time horizon. The available information technology makes it possible to depict procurement, production and distribution in one approach. Clearly, more details are at the expense of computing time. Therefore, selecting only relevant data requires a certain level of professional competence. Concerning 
the key components of supply chain modelling we refer to Min and Zhou [3]. In this way modelling becomes modular based. In other words, a basic model can be arbitrary reduced or extended in the constraints system. This facilitates the application even for unexperienced users. In the subsequent section we review quantitative supply chain models suitable for central stage-overlapping planning.

\subsection{Literature Review of Quantitative Multi-Stage Production-Distribution Approaches}

Geoffrion and Graves [7] were the first to address a multi stage production-distribution problem which refers to today's medium-term tactical supply chain planning problems. They incorporate single-sourcing constraints in their model and apply Bender's decomposition. Their pioneering contribution offers a helpful starting point for distribution planning. Glover et al. [8] develop an integrated computer-based production-distributioninventory system based on a network-model for a chemical company. Van Roy [9] presents a single period multi stage approach for coordinated production and distribution planning at a petrochemical company which incorporates transportation fleet optimization. Thereby, transportation planning is focused. Lee and Billington [10] apply a stochastic model for decentralized planning and control in a supply chain at Hewlett-Packard. The authors assume decentralized controlling as centralized planning may not be feasible due to organizational barriers between facilities. Here, a clear superordinate reference model can facilitate central planning. Martin et al. [11] describe the application of a Linear Program, termed FLAGPOL, and its benefits in the flat glass supply chain. Based on the results of the case study they state that integrated planning has many advantages compared to isolate planning in each plant. Pooley [12] presents a two stage mixed integer program for a Canadian dairy processor. Binary decision variables determine locations of supply chain members and customer oriented single sourcing. Production capacities, as well as warehousing capacities, are limited. Production and transportation is modeled in a single continuous decision variable. A rather widespread model is developed by Arntzen et al. [13]. They survey a global multi stage supply chain in the computer industry. Their extensive model features among other aspects duty considerations and offset trade. The model is characterized by a multi criteria objective function that seeks to minimize total costs and cycle time. Oxé [14] uses a Linear Program for the optimization of a two stage chemical supply chain. Production-, warehousing- and transportation costs are minimized. The author states that optimization models serve to compare several scenarios. Mixed integer models tend to require more computation time and are therefore less efficient in an iterative decision-making process. $\mathrm{He}$ indicates five minutes for computation of the presented LP using the AMPL-CPLEX software package. Ozdamar and Yazgac [15] present a deterministic model for the production-, distribution and transportation planning problem in a supply chain of a detergent company consisting of one central plant and multiple warehouses. Haehling von Lanzenauer and Pilz-Glombik [16] propose a Mixed Integer Linear Programming model for the tactical supply chain planning problem which considers order, production and transportation decisions as well as demand uncertainty. Their model is further implemented for a modified version of the Beer Distribution Game. Ferretti et al. [17] analyze the aluminum supply chain with the focus on alternative supply methods for aluminum. The authors integrate environmental aspects in the analytical description and evaluate the economic and environmental effects of the industrial practice. Gunnarsson et al. [18] design a single period optimization model for a biochemical company in which they aim to maximize total profits and coordinate decisions concerning production $\mathrm{mix}$ as well as contract and transportation mode selection. Pibernik and Sucky [19] treat tactical supply chain planning, which they denote with the likewise term supply chain master planning, in networks of independent companies based on a mixed integer linear program. The model is a modification of the Multi-Level Capacitated Lot Sizing Problem and includes setup constraints. They state that integrated superior plans are not accepted so that in general coordination is implemented in practice through iterative collaboration with operational plans. This so-called upstream planning leads to sub optimal plans compared to integrated plans. The authors propose an approach which applies partial centralization and benefit sharing. Steinrücke and Jahr [20] propose an extensive tactical model in the industrial transformer supply chain utilized in a decentralised coordination process.

\subsection{A Simple Extension of the Two-Stage- Production- Distribution-Problem}

In this section we consider a specific supply chain model which is suitable for network overlapping coordination as basis for a superior management concept presented in section three. We take the TwoStage-Production-Distribution-Problem

(TSPDP) 
formulated by Geoffrion and Graves [7] and extend it by multiple time periods.

\section{Symbols}

\section{Indices}

$\begin{array}{ll}\text { I } & \text { Production sites } \\ \text { J } & \text { Distribution centers } \\ \text { M } & \text { Transportation modes } \\ \text { P } & \text { Products } \\ \text { T } & \text { Planning horizon }\end{array}$

\section{Parameters}

$a_{\text {ip }} \quad$ Coefficient of technical capacity usage of product $p \in P$ at site $i \in I$

$b_{i p}$ Coefficient of personnel capacity usage of product $p \in P$ at site $i \in I$

$\mathrm{d}_{\mathrm{jpt}} \quad$ Demand for product $\mathrm{p} \in \mathrm{P}$ at distribution center $\mathrm{j}$ $\in \mathrm{J}$ in planning period $\mathrm{t} \in \mathrm{T}$

$\mathrm{kp}_{\mathrm{ip}}$ Unit production cost for product $\mathrm{p} \in \mathrm{P}$ at production site $i \in I$

$\mathrm{I}_{\mathrm{jp}} \quad$ Unit storage cost for product $\mathrm{p} \in \mathrm{P}$ at distribution center $\mathbf{j} \in \mathrm{J}$

$\mathrm{N}_{\mathrm{it}} \quad$ Maximum personnel capacity at production site $\mathrm{i}$ $\in \mathrm{I}$ in planning period $\mathrm{t} \in \mathrm{T}$

$\mathrm{tk}_{\mathrm{ijm}}$ Unit transportation cost for transportation mode $m \in M$ for shipments from production site $i \in I$ to distribution center $j \in J$

$\Psi_{\text {it }}$ Maximum technological capacity at production site $\mathrm{i} \in \mathrm{I}$ in planning period $\mathrm{t} \in \mathrm{T}$

$\varphi_{\mathrm{jt}} \quad$ Maximum storage capacity at distribution center $\mathrm{j}$ $\in \mathrm{j}$ in planning period $\mathrm{t} \in \mathrm{T}$

\section{Decision Variables}

$\mathrm{w}_{\mathrm{jpt}} \quad$ Storage level of product $\mathrm{p} \in \mathrm{P}$ at distribution center $j \in J$ in planning period $t \in T$

$x_{i j p t m}$ Production quantity of product $p \in P$ shipped from production site $i \quad \in$ to distribution center $\mathrm{j} \in \mathrm{J}$ in planning period $\mathrm{t} \in \mathrm{T}$ via transportation mode $\mathrm{m} \in \mathrm{M}$

The model can be formulated as follows:

Minimize

$\sum_{\mathrm{i} \in \mathrm{I}} \sum_{\mathrm{j} \in J} \sum_{\mathrm{p} \in \mathrm{P}} \sum_{\mathrm{t} \in \mathrm{T}} \sum_{\mathrm{m} \in \mathrm{M}}\left(\mathrm{kp}_{\mathrm{ip}}+\mathrm{tk}_{\mathrm{ijm}}\right) \cdot \mathrm{X}_{\mathrm{ijptm}}+\sum_{\mathrm{j} \in J} \sum_{\mathrm{p} \in \mathrm{P}} \sum_{\mathrm{t} \in \mathrm{T}} \mathrm{I}_{\mathrm{jp}} \cdot \mathrm{w}_{\mathrm{jpt}}$
Subject to

$$
\begin{aligned}
& \mathrm{d}_{\mathrm{jpt}}+\mathrm{w}_{\mathrm{jpt}}=\sum_{\mathrm{i} \in \mathrm{I}} \sum_{\mathrm{m} \in \mathrm{M}} \mathrm{X}_{\mathrm{ijptm}}+\mathrm{w}_{\mathrm{jpt}-1} \quad \forall \mathrm{j} \in \mathrm{J}, \forall \mathrm{p} \in \mathrm{P}, \mathrm{t} \in \mathrm{T} \\
& \sum_{\mathrm{j} \in \mathrm{J}} \sum_{\mathrm{p} \in \mathrm{P}} \sum_{\mathrm{m} \in \mathrm{M}} \mathrm{a}_{\mathrm{ip}} \cdot \mathrm{x}_{\mathrm{ijptm}} \leq \psi_{\mathrm{itt}} \quad \forall \mathrm{i} \in \mathrm{I}, \forall \mathrm{t} \in \mathrm{T} \\
& \sum_{\mathrm{j} \in \mathrm{J}} \sum_{\mathrm{p} \in \mathrm{P}} \sum_{\mathrm{m} \in \mathrm{M}} \mathrm{b}_{\mathrm{ip}} \cdot \mathrm{x}_{\mathrm{ijptm}} \leq \mathrm{N}_{\mathrm{it}} \quad \forall \mathrm{i} \in \mathrm{I}, \forall \mathrm{t} \in \mathrm{T} \\
& \sum_{\mathrm{p} \in \mathrm{P}} \mathrm{w}_{\mathrm{jpt}} \leq \varphi_{\mathrm{jt}} \quad \forall \mathrm{j} \in \mathrm{J}, \forall \mathrm{t} \in \mathrm{T} \\
& \mathrm{x}_{\mathrm{ijptm}} ; \mathrm{w}_{\mathrm{jpt}} \geq 0 \quad \forall \mathrm{i} \in \mathrm{I}, \forall \mathrm{j} \in \mathrm{J}, \forall \mathrm{p} \in \mathrm{P}, \forall \mathrm{t} \in \mathrm{T}, \forall \mathrm{m} \in \mathrm{M}
\end{aligned}
$$

The analytical planning model comprises two supply chain stages. In the first stage several production sites $i \in I$ produce the products $p \in P$ and supply several distribution centers $j \in J$ on the second stage. These have to meet dynamic regional demand $d_{j p t}$ for each product in each planning period $t \in T$. For transportation processes the production sites can use several transportation modes $m \in M$. The goal is to meet the dynamic demand at minimal costs. The objective function includes production and transportation costs and storage cost. Therefore, the production-, distribution and transportation processes have to be coordinated cost minimal between the locations in the supply chain network. As the decision problem covers multiple planning periods the production-transportation quantities have to be balanced according to the available capacities. The balance equation (1) is the most important part of the model structure. It coordinates the material flows and storage levels within the model so that the demand is met in every planning period at minimal costs. Produced and transported production quantities $x_{i j p t m}$ in each period must be large enough to satisfy the demand $d_{j p t}$ and the required storage level at the end of the planning period $w_{j p t}$ which is needed to balance dynamic demand in following periods. For this also existing stocks at the beginning of the planning period $w_{j p t-1}$ which have been established in previous periods can be used. In restrictions (2) and (3) technological as well as personnel capacities can be distinguished. The coefficients $a_{i p}$ and $b_{i p}$ can be varied according to the specific production situation. This allows for a heterogeneous consideration of the production sites. Constraint (4) restricts the available storage capacities at the distribution centers. Finally, constraint (5) defines the range for the decision variables. The planning model implies a discrete planning horizon with several sub-planning periods. We chose this depiction based on the hierarchical planning philosophy. The challenge is to create an efficient coordination process around 
this model (or similar quantitative models) to enable transparent coordination of supply chain processes. Therefore, we introduce a pivotal point supply chain management reference model in the next section.

\section{A REFERENCE MODEL FOR INTEGRATED QUANTITATIVE PIVOT POINT SUPPLY CHAIN MANAGEMENT}

\subsection{Literature Review of Supply Chain Reference Models}

The probably most common supply chain reference model is the Supply-Chain-Operations-ReferenceModel (SCOR) which was developed by the supplychain-council in 1996 [21]. It is a general framework which depicts the five main network processes plan, source, make, deliver and return. These processes are stepwise treated on four hierarchical levels. Through its general structure the SCOR model is suitable for any supply chain. However, even though various management concepts can be applied within the framework, the SCOR only offers a qualitative approach. As a result, the efficiency of the approach strongly depends on individual expertise and the possibility to enforce standards. Nevertheless, this is a crucial aspect in multi-tier networks with independent partners where arrangements must be stipulated. There, objective plans are needed for mid-term management. Cooper et al. [1] present an approach to combine the three functional areas business processes, supply chain structure and management components. There are seven main processes defined which are structured by the management components. This rather basic depiction of supply chain management ignores that there are directed planning procedures, e.g. from long-term structures to shortterm deliveries, which must be included. Stadtler [22] introduces the House-of-Supply-Chain-Management. The pillars of supply chain management are integration and coordination whereas the operational artefacts are the foundations. Therewith it focuses on the crucial elements to establish transparent communication and resilient structures. This is a more widespread approach than for example the SCOR model. In turn, the concept must be supplemented with explicit quantitative models for each stage of the management process. Therefore it only offers a general framework. Rohde et al. [6] present the Supply-Chain-PlanningMatrix which directly refers to the hierarchical planning philosophy. The different planning tasks are arranged down the time axis starting with long-term (strategic) tasks. Like the other reference models this concept aims at connecting all relevant supply chain functions. But, it also shows the detailed planning contents as well as the linkages between long-term and short-term processes. This is important for quantitative model building. Yet, it does not focus on modelling as core activity and therefore disregards possible advantages within a coordination process.

\subsection{Integrated Pivotal Point Supply Chain Management}

Let us assume that business partners within a network share a common understanding of collaboration. All parties involved agree that a transparent cooperation is more advantageous than individual and maybe opportunistic arrangements in stages. Admittedly, this requires a very high level of insight in the nexus of individual and collective goals from each partner. We therefore introduce a reference model for inter- and intracompany coordination of production-distribution processes. The model combines elements proposed by Stadtler [22] and Rohde et al. [6] (see Section 3.1). The processes mainly focus on production-distribution, because these are the central activities in supply chains. As the mathematical approaches are not limited to a specific industry the pivotal point model is in general suitable for any supply chain. Figure 2 shows a repeating planning and management process with quantitative supply chain modelling at its centre.

\subsubsection{Superior Network Collaboration}

At the beginning there is the economic collaboration design. In business networks with legally and economically independent partners the cooperation is not a self-evident fact. Each business naturally pursues individual goals. So, every partner must be convinced that complying with network arrangements, which are collectively reasonable, is individually advantageous or at least not disadvantageous. The entire network stability before and during the cooperation depends on the partners' willingness to full compliance. Hereby, the model's generated plan shows position, jobs and interdependences over time. Thus, uncertainties concerning the operational tasks are overcome, forming confidence in the network. Additionally, the distribution of financial burden and benefits must be stipulated. This includes that partners who potentially benefit more than others from the network cooperation must be willing to share profits. The recurring stipulation of general collaboration conditions leads to some model fine-tuning. 


\subsubsection{Network Processes Coordination}

When the strategic network design is fixed, the tactic processes must be coordinated. These predominantly focus on procurement, production and distribution of raw materials and finished product quantities in the network from the suppliers to the customers. The plan sets the mid-term standards, e.g. material flow paths between supply chain stages and locations, capacity usages and supply quantities. These standards consider reported capabilities of specific locations, i.e. if a location provides no capacities for the network in a time period then it is left out of the computed plan.

\subsubsection{Individual Business Processes}

The tactical network plan determines the scope for the short-term planning of network jobs. Each business integrates the network jobs into their individual production planning which includes both, the network internal jobs and the individual external jobs. On this short-term level businesses evaluate whether external jobs or network jobs are given priority. In order to avoid that the tactical network jobs are endangered, the plan must be flexible and resilient enough. This can be achieved by big-bucket modelling.

\subsubsection{Targets Re-Adjustment}

For the next network planning iteration the partners verify their intention to maintain their membership in the current supply chain network. Therefore, they reconcile their market plans with the current network targets. Potential contradictions require stipulations and determine new perimeter for the quantitative model. This, in turn, initiates the strategic planning including the long-term goals and the economic design of the supply chain model and the collaboration.

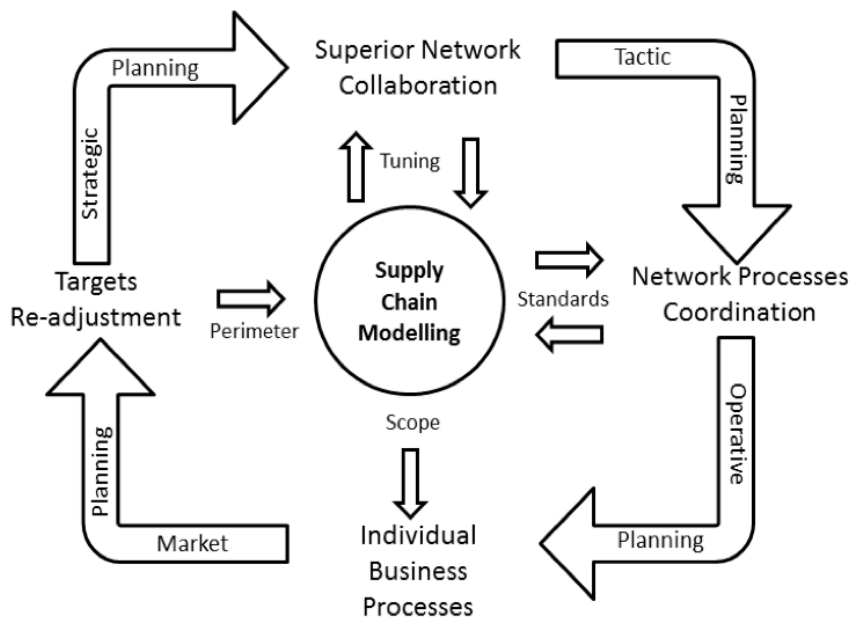

Figure 2: Pivotal point supply chain management.

\section{CONCLUDING REMARKS}

The main purpose to focus a quantitative model in the supply chain management is to create transparency and facilitate decision making. Each partner utilises the same information base and can align individual conditions to the network requirements. By this, confidence in the collaboration is strengthened to guarantee network stability. The eventual outcome of a quantitative model is a plan which can be either used as benchmark or fixed target. Both gives decision makers a base to foresee the planning of process times and quantities. The pitfalls for this approach are reservations against mathematical modelling and disclosure of sensible data, e.g. capacities, demands and cost rates. However, it seems inevitable to use mathematical support, as accelerated global competition enforces shorter decision paths. The adherence to a few conditions can help generate clear mathematical models. These are for example modular model structures, big-bucket-modelling and the consideration of only decision relevant data. The consistent implementation in information systems and available software offers furthermore a simple handling. There are promising attempts to utilise similar approaches [20, 23]. These show that based on information system usage quantitative decision support can be more than a tool. It builds the base of any efficient business management. So, the possibilities of modern information technology and the modular model building undermine reservations against quantitative management. Modern managers must rethink and open towards mathematical modelling which is no longer a simple component of operational research. It is management in the proper sense.

\section{REFERENCES}

[1] Cooper MC, Lambert DM, Pagh, JD. Supply chain management: More Than a New Name for Logistics. IJLM 1997; 8: 1-14. http://dx.doi.org/10.1108/09574099710805556

[2] Beamon, BM. Measuring supply chain performance. IJOPM 1999; 19: 275-292. http://dx.doi.org/10.1108/01443579910249714

[3] Min H, Zhou G. Supply chain modeling: past, present and future. Comp Ind En 2002; 43: 231-249. http://dx.doi.org/10.1016/S0360-8352(02)00066-9

[4] Lee LH, Padmanabhan V, Whang S. Information Distortion in a Supply Chain: The Bullwhip Effect. Manag. Sci. 1997; 43 546-558. http://dx.doi.org/10.1287/mnsc.43.4.546

[5] Sherman RJ. Collaborative Planning, Forecasting \& Replenishment (CPFR): Realizing the Promise of Efficient Consumer Response through Collaborative Technology. JMTP 1998; 6: 6-9.

[6] Rohde J, Meyr H, Wagner M. Die Supply Chain Planning Matrix. PPS Manag. 2000; 5: 1-15. 
[7] Geoffrion AM, Graves GW. Multicommodity Distribution System Design by Benders Decomposition. Manag. Sci. 1974; 20: 822-844. http://dx.doi.org/10.1287/mnsc.20.5.822

[8] Glover F, Jones G, Karney D, Klingman D, Mote J. An Integrated Production, Distribution, and Inventory Planning System. Interfaces 1979; 9: 21-35. http://dx.doi.org/10.1287/inte.9.5.21

[9] van Roy TJ. Multi-Level Production and Distribution Planning with Transportation Fleet Optimization. Manag. Sci. 1989; 35: 1443-1453.

http://dx.doi.org/10.1287/mnsc.35.12.1443

[10] Lee HL, Billington C. Material Management in Decentralized Supply Chains. Op Re 1993; 41: 835-847. http://dx.doi.org/10.1287/opre.41.5.835

[11] Martin $\mathrm{CH}$, Dent DC, Eckhart JC. Integrated Production, Distribution, and Inventory Planning at Libbey-Owens-Ford. Interfaces 1993; 23: 68-78. http://dx.doi.org/10.1287/inte.23.3.68

[12] Pooley, J. Integrated Production and Distribution Facility Planning at Ault Foods. Interfaces 1994; 24: 113-121. http://dx.doi.org/10.1287/inte.24.4.113

[13] Arntzen BC, Brown GG, Harrison TP, Trafton LL. Global Supply Chain Management at Digital Equipment Corporation. Interfaces 1995; 25: 69-93.

http://dx.doi.org/10.1287/inte.25.1.69

[14] Oxé G. Reducing overcapacity in chemical plants by linear programming. EJOR 1997; 97: 337-347. http://dx.doi.org/10.1016/S0377-2217(96)00202-0

[15] Ozdamar L, Yazgac T. A hierarchical planning approach for a production-distribution system. IJPR 1999; 37: 3759-3772. http://dx.doi.org/10.1080/002075499190031
[16] Haehling von Lanzenauer CH, Pilz-Glombik K. Coordinating supply chain decisions: an optimization model. OR Spec 2002; 24: 59-78. http://dx.doi.org/10.1007/s291-002-8200-3

[17] Ferretti I, Zanoni S, Zavanella L, Diana A. Greening the aluminium supply chain. IJPE 2007; 108: 236-245. http://dx.doi.org/10.1016/j.ijpe.2006.12.037

[18] Gunnarsson H, Rönnqvist M, Carlsson D. Integrated Production and Distribution Planning for Södra Cell AB. JMMA 2007; 6: 25-45. http://dx.doi.org/10.1007/s10852-006-9048-z

[19] Pibernik R, Sucky E. An approach to inter-domain master planning in supply chains. IJPE 2007; 108: 200-212. http://dx.doi.org/10.1016/j.ijpe.2006.12.010

[20] Steinrücke $M$, Jahr M. Tactical planning in supply chain networks with customer oriented single sourcing. IJLM 2012; 23: $259-279$. http://dx.doi.org/10.1108/09574091211265387

[21] APICS Supply Chain Council [homepage on the Internet]. APICS, 8430 West Bryn Mawr Avenue Chicago, IL 60631 USA; [cited 2015 Jun 22]: Available from: http://www.supplychain.org/

[22] Stadtler, H. Supply chain management and advanced planning-basics, overview and challenges. EJOR 2005; 163: $575-585$.

http://dx.doi.org/10.1016/j.ejor.2004.03.001

[23] Jahr M. A Hybrid Approach to Quantitative Software Project Scheduling Within Agile Frameworks. PMJ 2014; 45: 35-45. http://dx.doi.org/10.1002/pmj.21411

() 2015 Michael Jahr; Licensee Lifescience Global.

This is an open access article licensed under the terms of the Creative Commons Attribution Non-Commercial License (http://creativecommons.org/licenses/by-nc/3.0/) which permits unrestricted, non-commercial use, distribution and reproduction in any medium, provided the work is properly cited. 